\title{
Reescribiendo Casa de muñecas como respuesta crítica a la desigualdad de las mujeres durante el franquismo
}

\author{
Iris Muñiz (Universidad de Oslo, Noruega)
}

\begin{abstract}
A Doll's House [Et Dukkehjem, 1879] is Henrik Ibsen's best known and most widely performed play. In Spain, it was Ibsen's first translated play, in 1892, and it has been translated, published, staged and rewritten multiple times since then. This article analyses three stage rewritings by Ana Diosdado (19382015) and Lucía Miranda (1982- ) that have as a common element their Francoist references that were used to make the plot more relatable for the Spanish audience. Therefore this article studies how the reception and interpretation of $A$ Doll's House in contemporary Spain has been influenced by the self-perception of the backwardness of the country in relation to women's emancipation during Francoism, which made the situation of women in that period comparable to that of Nora in 1870s Norway.
\end{abstract}

Keywords: Ibsen's reception in Spain, Translations and adaptations of $A$ Doll's House, Francoist culture, women's history, historical memory.

\section{Introducción}

Casa de muñecas (1879) [Et Dukkehjem] es la obra de Henrik Ibsen más conocida, traducida y representada a nivel global. La razón principal del éxito de la obra desde el momento de su estreno está estrechamente relacionada con la problemática social que plantea con respecto a la situación desigual de las mujeres dentro del matrimonio, algo que destacan los autores del reciente monográfico A Global Doll's House (2016). En tanto que el personaje de Nora fue entendido como una representación de la emergente subjetividad femenina moderna, su famoso portazo final se interpreta como un símbolo de la lucha por la igualdad entre hombres y mujeres (Holledge et al 2016: 10). Si este era uno de los asuntos más candentes en la Europa de finales del siglo XIX, no lo sigue siendo menos en otros países del mundo más de cien años después, puesto que la lucha por la igualdad sigue vigente, pese a los enormes avances alcanzados por el feminismo. Esta vinculación ideológica explica por ejemplo que la obra no fuera introducida hasta finales del siglo XX en varios países de cultura islámica (Holledge 2011).

Aunque se ha querido buscar la misma explicación para justificar la pretendida escasez de representaciones en países de habla hispana, esta asunción es doblemente errónea puesto que esa escasez no es tal, sino que corresponde a una falta de información sistematizada sobre los eventos teatrales en el extenso mundo hispanohablante, como veremos más adelante, y además las reivindicaciones feministas en el mundo hispanohablante se desarrollaron en sus inicios en paralelo al resto del mundo occidental, es decir, en el cambio de siglo. Es cierto, sin embargo, que a lo largo del siglo XX diversos países del ámbito hispano experimentaron regímenes 
dictatoriales que limitaron significativamente la libertad de expresión de sus pueblos, cortando los derechos humanos y particularmente la igualdad de género, en tanto que se priva a las mujeres de su condición de personas y ciudadanas. Así, se construyen "discursos de normalización social defensores de un orden sexo-genérico que imponía elementos homogeneizadores sobre hombres y mujeres" y reducía a las mujeres a un papel secundario, de reproducción y cuidado, "obviando otras problemáticas sobre el colectivo mujer como clase social” (Tessada Sepúlveda 2012: 266). Es por ello que, en los regímenes autoritarios, basados en una organización social patriarcal tradicional, se fomenta el papel de la mujer como cuidadora y reproductora, en sus papeles de madre y esposa (Ruiz Franco 2007: 25). Es decir, los papeles que Torvald recuerda a Nora que deben de ser sus "deberes" más "sagrados" (Ibsen \& Diosdado 1983: 95; Diosdado 1977[1975]: 61; Miranda 2015: 120); en original "dine helligste pligter" (HIS 370). Es natural, por tanto, que la obra de Casa de muñecas, que problematiza el rol exclusivo de la mujer como esposa y madre, haya sido entendida como espejo literario de la situación real de las mujeres sometidas a los diversos regímenes dictatoriales que florecieron en el mundo hispano a lo largo del siglo XX.

En el caso concreto del franquismo, la opresión contra las mujeres significó una pérdida total de sus "derechos políticos y civiles" y un "estricto control moral" (Moreno 2013: 3). En tanto que la ideología fascista consideraba la familia como el elemento base de organización nacional, garante del orden ciudadano, "los fascistas lucharon contra la independencia femenina porque era un valor que contradecía la subordinación" (Molinero 1998: 100). Por otra parte, la nueva legislación franquista, que rompe con los avances legales de la II República, supuso en gran medida un retorno a los "códigos civiles napoleónicos" que se basaban en la "consideración de que la mujer era incapaz de actuar por cuenta propia y alguien debía ayudarla", un tutor legal siempre masculino, primero el padre, luego el marido, o el pariente masculino más cercano si no se casaba (Domingo 2007: 94-95; Ruiz Franco 2007: 35-47). Así, las mujeres quedaban marginadas "social, económica y profesionalmente" (Domingo 2007: 100). De esta forma se establece "por ley una orden de género de dominio masculino" que relegaba a la mujer a la domesticidad y a un rol subalterno con respecto a los hombres (Nash 2013: xii). Por tanto, la desigualdad de género era intrínseca a la sociedad franquista.

La legislación franquista paternalista negaba la subjetividad y los derechos individuales de las mujeres y las consideraba seres subalternos relegados "a una función social específica basada en su capacidad reproductora y maternal” (Ruiz Franco 2007: 27). Así, se asumía que las mujeres poseían una "natural disposición al sacrificio y la abnegación" (Domingo 2007: 121), es decir, a supeditar su vida e intereses personales a la familia. Asimismo, el ideal femenino Nacional-Católico de "madre y esposa resignada y cristiana" significaba que los roles de esposa y madre no solo eran "un orgullo privado, sino también una obligación patriótica" (Morcillo 2013: 72-73). Así, los estatutos de la Sección Femenina de la Falange Española, órgano principal de gestión de asuntos femeninos durante el Franquismo, "el fin esencial de la mujer (...) es servir de perfecto complemento al hombre". En paralelo, la función de la Sección sería "auxiliar y complementar" con "misión, sentido y estilo netamente femeninos la obra viril de la Falange", cumpliendo así "las funciones de la mujer en el hogar: arreglo material, aliento y cuidado" (Estatus Sección Femenina 1939). Las palabras de la ideóloga falangista Carmen Werner Bolín sintetizan perfectamente esta idiosincrasia, al afirmar que "nada complace tanto a la psicología masculina como la sumisión de la mujer, y nada complace tanto a la psicología femenina como la entrega sumisa a la autoridad masculina (Werner 1954: 55). En definitiva, desde la ideología domesticadora dominante en el franquismo (versión diluida del falangismo, 
variante española del fascismo), se buscaba una sublimación de las supuestas cualidades femeninas de sumisión y abnegación a los maridos, hijos, padres o cualquier miembro masculino de la familia o de la sociedad. En ese contexto, la Nora de Ibsen no tenía posibilidad de escapatoria alguna. Por eso reviste tanto interés estudiar la interpretación e interacción de la obra de Ibsen como revisión de la situación de las mujeres en el contexto del franquismo.

En este artículo examinaré brevemente tres reescrituras españolas que tienen como marco de referencia la dictadura franquista en España: "Nora" (1975) y Casa de muñecas (1983) de Ana Diosdado y Nora, 1959 (2015) de Lucía Miranda. Aunque únicamente uno de los textos fue publicado en vida de Franco, los tres textos comparten un imaginario interpretativo común de crítica a la situación de las mujeres en el franquismo y postfranquismo, de forma implícita o explícita, como explicaré en cada caso. Es por eso que es importante subrayar que este artículo no pretende estudiar de qué forma Casa de muñecas fue adaptada durante el franquismo, sino de qué forma, adaptaciones escritas justo al cierre del mismo, o con posterioridad, hacen referencia crítica al franquismo, y en concreto a la situación de las mujeres durante esa época.

Si las primeras reivindicaciones feministas que surgieron en Europa al cierre del siglo XIX (lo que se suele conocer como el feminismo de primera ola) proporcionaron el caldo de cultivo en que se creó y recibió Casa de muñecas por primera vez, no resulta de extrañar que en la búsqueda por la recuperación de la igualdad de género del tardofranquismo y la transición se renovara el interés por la inmortal obra de Henrik Ibsen. Como ha señalado Sirkuu Aaltonen, las producciones teatrales tienen una dimensión social, cultural e histórica de forma que las traducciones/adaptaciones teatrales son más bien espejos de la cultura meta en vez de ventanas hacia la cultura fuente (Aaaltonen 2000:112). Por tanto, en el contexto franquista es posible entender cómo Casa de muñecas de Ibsen funciona como un espejo donde representar y rebatir la domesticidad impuesta de la simbólica casa de muñecas franquista donde tantas mujeres quedaban relegadas de la vida pública.

\section{Reescribiendo Casa de muñecas para el público hispanohablante}

En las primeras líneas de este trabajo hemos hecho hincapié en el hecho de que Casa de muñecas es la obra de Henrik Ibsen más conocida por el público hispanohablante. La primera traducción de la obra al español fue publicada en la revista La España Moderna en 1892 (Muñiz 2016). La obra continúa editándose con regularidad desde entonces a ambos lados del Atlántico, y en librerías y bibliotecas se encuentran numerosas versiones de diversos traductores, aunque la mayoría de ellas son traducciones indirectas, es decir, que utilizan una lengua distinta al noruego como fuente. Además, la obra no ha dejado de representarse, en diversas formas, en los últimos ciento veinte años. Refiriéndose a cifras vigentes mientras el libro estaba siendo redactado, los autores de A Global Doll's House (2016) contabilizan 3787 realizaciones escénicas de Casa de muñecas en 35 idiomas y 87 países, incluyendo producciones teatrales, radiofónicas, cinematográficas y televisivas. Sin embargo, en la base de datos «IbsenStage», creada por el Centro de Estudios Ibsen de la Universidad de Oslo, de la que bebe dicha publicación, solamente aparecen unos 100 registros de realizaciones escénicas en español entre España y Latinoamérica (en contraste con los más de 4000 registros en todos los países e idiomas). Por otra parte, la inmensa mayoría de los registros en lengua española de «IbsenStage» corresponden a obras estrenadas en los últimos treinta años, lo cual ejemplifica 
la necesidad de hacer un análisis exhaustivo de la prensa teatral en busca de adaptaciones más antiguas.

Un factor importante para comprender la recepción española de Casa de muñecas es la existencia de numerosas adaptaciones libres de esta y otras obras de Ibsen. Ejemplos singulares serían la versión hispanizada de María y Gregorio Martínez Sierra titulada Mamá (1913), llevada al cine en 1931 (Muñiz 2018), o la más reciente obra de Daniel Veronese El desarrollo de la civilización venidera (2009), reescritura de Casa de muñecas con elementos prestados de Hedda Gabler que se puso en escena a ambos lados del Atlántico. Además, son varias las llamadas continuaciones, es decir, aquellas obras que toman o bien el personaje principal o el conflicto de la obra como punto de partida para un nuevo drama. Como continuaciones, Eduardo Pérez-Resilla señala obras como Nora obri la porta (1989) de María José Ragué, Armonía Rodríguez e Isabel Clara Simó, ¿Qué hizo Nora cuando se marchó? (1994) de José Ramón Fernández, o Te quiero muñeca (2001) de Ernesto Caballero (Pérez Resilla 2009: 2426). Sería necesario incluir en este apartado obras recientes como El regreso de Nora (2009) de Miguel Murillo, Nora, la mujer que se hace libre (2011) de María Martínez de Tejada, o Querido Ibsen, soy Nora (2014) de Griselda Gambaro.

Mención aparte merecen las producciones para la pantalla. Por ejemplo, la primera adaptación al cine se realizó en 1943 en Argentina, bajo la dirección de Ernesto Arancibia (Dubatti 2006). El texto, que se toma muchas libertades con respecto al original de Ibsen, fue firmado por el dramaturgo español Alejandro Casona, exiliado republicano en Argentina, donde colaboró asiduamente como guionista en la llamada Edad de Oro del cine argentino. También existe una adaptación cinematográfica mexicana de 1954, dirigida por el cineasta alemán exiliado Alfredo Crevenna (Grovas Hajj 2008). Ambas películas alteran el final estipulado por Ibsen, haciendo regresar a Nora a la casa, tras un intervalo de unos años. El texto ha sido también adaptado para la pequeña pantalla en más de media decena de ocasiones. En España, la obra de teatro fue emitida en televisión en 1964 dentro del formato Primera Fila, bajo la dirección de Juan Guerrero Zamora, otra vez en 1967 para Teatro de Siempre, bajo la dirección de Ricardo Lucía, y de nuevo en 1971 bajo la dirección de Josefina Molina, para una nueva entrega del televisado Teatro de Siempre. Más reciente es la versión de Estudio 1 para TVE en 2002, dirigida por Manuel Armán. A estas adaptaciones televisadas habría que sumar otras en México, Argentina y otros países latinoamericanos, algunas de las cuales están registradas en Internet Movie Database. En paralelo, debemos tener en cuenta las adaptaciones radiofónicas ya que el teatro radiado o radioteatro, que normalmente abrevia considerablemente la longitud de la obra, era una forma común de entretenimiento a mediados del pasado siglo y podemos suponer que hubo varias adaptaciones radiofónicas a ambos lados del Atlántico. He podido encontrar, por ejemplo, una versión emitida en Radio Madrid en 1970 de apenas 50 minutos. Puesto que los datos contrastados existentes son insuficientes, sería muy necesario realizar un análisis exhaustivo de las adaptaciones de Casa de muñecas y obras de Ibsen al cine, televisión y radio en el mundo hispánico.

Las primeras producciones escénicas en castellano, con texto firmado por Francisco Fernández Villegas fueron en 1902 y 1908 (Muñiz 2016: 5). La siguiente puesta en escena fue en 1917, con texto de María y Gregorio Martínez Sierra. En paralelo a las producciones en español, hubo una rica recepción de Ibsen en lengua catalana (Siguán 2003). La producción teatral más conocida durante el franquismo fue la versión de Mercedes Ballesteros sobre texto de Ibsen estrenada en el teatro Eslava en 1961. Empero, aunque tradicionalmente se ha pensado que esta fue la única, en el Archivo General de la Administración de Alcalá se conservan 
documentos de producciones escénicas aprobadas por la censura que aún no han sido registrados en ninguna base de datos y que se corresponden en su mayoría con teatros pequeños de provincias. Por ello se puede estimar que, en conjunto con las versiones televisadas y radiofónicas, Casa de muñecas se produjo al menos una docena de veces durante el franquismo lo cual apunta hacia al interés continuado por la obra que rubrica nuestra hipótesis inicial sobre el hecho de que la obra de Ibsen pudo interpretarse como un espejo de las condiciones sociales de la España franquista.

En lo que se refiere a las adaptaciones escénicas, es importante señalar que a veces es difícil saber cuál ha sido el grado de libertad que se tomaron los adaptadores escénicos sobre el texto de Ibsen ya que estas nuevas versiones escénicas frecuentemente conservan el título original, pero mencionan que ha habido una revisión, versión, adaptación, o dramaturgia nueva. Este es un ilustrativo ejemplo del problema terminológico ya señalado. Repasando las producciones tituladas Casa de muñecas que aparecen en el registro de la base de datos del Centro de Documentación Teatral de España (14 producciones originales en lengua castellana, de directores diferentes, entre 1983 y 2015) hay cinco que mencionan a un segundo autor: la "revisión" de Ana Diosdado en 1983 en Barcelona, la "adaptación” de Javier Mañón en 1996 en Oviedo, la "adaptación" de 2008 de Marli Santana en Gijón, la "dramaturgia” de Manuel Carcedo de 2009 en Madrid, y la "versión" de Jerónimo Corenlles y Ximo Flores de 2013 en Valencia. La única publicada, la adaptación de Diosdado, presenta cuantiosas modificaciones textuales, como veremos más adelante.

La brevedad de este artículo no permite profundizar en las problemáticas que presenta la traducción (y adaptación) teatral y la responsabilidad intelectual del traductor-adaptador sobre el texto meta. Sin embargo, hay un par de puntos teóricos que me gustaría subrayar ya que resultan claves para entender la confusa coexistencia de términos como traducción, adaptación $u$ otros como versión o recreación en el caso del teatro, lo que apunta a la indefinición de la nomenclatura y a la posible doble (o múltiple) autoría que suele presentarse en los textos teatrales trasplantados a otros idiomas y otras culturas. Es frecuente que los traductores (y directores, a veces la misma persona) quieran dejar su propia impronta sobre el texto en un grado mucho mayor que en el de otro tipo de traducciones. Sin embargo, los estudios de caso demuestran que es "imposible" determinar si realmente existe una relación cuantificable entre el "grado de libertad" que ejerce un traductor o adaptador cuando adapta una obra de teatro a su cultura meta y "el nombre que utiliza para denominar su artefacto", sea traducción, adaptación, versión o cualquier otro (Minier 2014: 14). En definitiva, que la relación entre texto fuente y texto meta en la traducción teatral es marcadamente "asimétrica", como apuntan Terry Hale y Carole-Anne Upton, puesto que con frecuencia los originales son no ya "distorsionados" sino reescritos con la intención de ajustarlos al momento de la recepción (Hale y Upton 2000: 9). Por ese motivo el concepto de reescritura, entendido como una forma de englobar la multiplicidad de modificaciones que se pueden introducir en un texto fuente para "adaptarlo" a una cultura meta y sus "expectativas ideológicas y poéticas" (Lefevere 1992: 8) es particularmente uso para el estudio de los textos teatrales reubicados en otras lenguas y otras culturas, evitando la confusión terminológica. Por ese motivo, he preferido utilizar el término reescritura a la hora de hablar de las plurales interpretaciones escénicas de Casa de muñecas que son objeto de estudio en este artículo. Parece evidente que la variedad de nomenclatura de las traducciones teatrales obscurece en vez de aclarar la ambigüedad de la posible doble autoría de la traducción teatral, y por ese motivo, es preferible hablar de reescritura como hacemos en este artículo. 


\section{Reescrituras de Ana Diosdado}

La actriz, directora y dramaturga Ana Diosdado (1938-2015) firmó la primera versión de Casa de muñecas que se puso sobre las tablas en la España democrática, una versión libre con escenas añadidas y recortadas que se basaba en una traducción literal de la reputada traductora noruega Kirsti Baggethun (López Sancho 1983: 63). Su vinculación con la obra de Ibsen venía de mucho antes ya que era hija del actor Enrique Diosdado, quien encarnó a Helmer en la versión de 1961 de Casa de muñecas, lo que le permitió familiarizarse tras las bambalinas con los entresijos de la obra. Sin embargo, para comprender la posición feminista de Ana Diosdado frente a Casa de muñecas de Ibsen es necesario estudiar el poco conocido discurso teatralizado o monólogo que dio en 1975 con ocasión del día internacional del teatro, unos meses antes de la muerte de Francisco Franco.

"Nora" (1975) se articula como un largo monólogo metateatral de más de 4000 palabras que Ana Diosdado interpreta además de escribir, y en el que reivindica la importancia del personaje para el teatro universal, aludiendo también a las conexiones existentes entre la situación de Nora en la Noruega decimonónica y la de las mujeres españolas en el tardofranquismo. El carácter reivindicativo del monólogo, y la crítica hacia la desigualdad de género en el franquismo se hacen explícitos desde los primeros párrafos en los que con ironía denuncia el machismo inherente a la patronímica tradicional según la cual las mujeres toman sus apellidos de otros nombres, sean padres o maridos:

Las mujeres siempre llevamos el apellido de algún hombre, y particularmente si este hombre es el marido, y no el padre, esto se considera, por alguna razón que se me oculta, como un regalo. Durante muchos años se ha empleado la frase de: "Él le dio su apellido", y se decía con un fondo de coro celestial, con ciertos toques de marcha militar también. Que yo sepa - realmente yo sé muy poco, no soy una mujer culta -, pero que yo sepa no ha habido épocas conocidas en que la mujer le haya dado al hombre su apellido. Bueno, sí, ha habido casos y los hay. Ha habido madres que han dado su apellido a sus hijos, pero no se ha considerado jamás un regalo, sino todo lo contrario, una vergüenza, como una rémora, como un hándicap importante para muchas cosas. Esto, que, en cierto modo, es anecdótico, no deja de ser significativo (Diosdado 1977 [1975]: 58).

Aunque la tradición patronímica española es menos androcentrista que la de la mayoría de los países occidentales ya que las mujeres casadas no pierden su apellido de nacimiento, la autora quiere destacar la problemática de las madres solteras que, al dar únicamente su apellido a sus hijos, sufren el ostracismo social. La reivindicación de los derechos de las madres solteras y de sus hijos fue uno de los temas candentes del renaciente movimiento feminista de finales de los años 70 en España.

A continuación, la Nora de Diosdado recuerda a los espectadores su historia, es decir, la trama de Casa de muñecas, haciendo particular hincapié en la condena social que su decisión de irse de la casa conyugal provocó en las audiencias de todo el mundo porque así rompía con la domesticidad y femineidad esperada del tipo de personaje que había encarnado al comienzo de la obra. El resumen de la trama está intercalado con frecuentes 'apartes' en los que Diosdado, por boca de Nora, relaciona los sucesos de la obra con reflexiones de carácter feminista sobre las desigualdades a las que se enfrenta Nora (y cualquier mujer) en la sociedad decimonónica y también en la actual española. Es particularmente interesante la siguiente:

Yo no podía pedir legalmente un préstamo. Una mujer casada no puede pedir un préstamo legal sin el consentimiento expreso de su esposo. Perdón, no puedo evitar una ligera 
confusión de épocas y de años. Se me olvida que ha pasado tanto tiempo. En 1879, una mujer casada no podía pedir un préstamo legal sin el consentimiento de su esposo, ahora estamos en 1975 y... ¿tampoco?... ¿y un marido puede pedir ese famoso préstamo sin el consentimiento expreso de su mujer?... ¿Sí?... ah...bien (...) El caso es que él me prestó el dinero, pero claro, mediante un recibo. Recibo que, por supuesto, tenía que avalar un hombre: mi firma no significaba nada; mi palabra, menos. Una mujer no es un ser adulto y responsable, al menos no lo era en 18... bueno, es igual (Diosdado 1977: 59).

Como vemos en esta reflexión se hace un paralelismo explícito (y una crítica implícita) al hecho de que la situación legal de las mujeres españolas en el tardofranquismo es la misma de las mujeres noruegas en 1879, es decir, que puesto que no son consideradas "un ser adulto y responsable" no pueden pedir préstamos. En una escena de su adaptación de 1983 vuelve a insistir en este punto: "Porque estás casada. No puedes pedirlo sin consentimiento de tu marido" (Diosdado 1983: 21). Como apunta Aurora Morcillo, según la legislación franquista las mujeres sólo podían abandonar la casa paterna si se casaban, se hacían monjas o su padre contraía segundas nupcias, y, una vez casadas, "no tenían derechos sobre la custodia de los hijos, o independencia económica o legal" (Morcillo 2013: 81).

Un poco más adelante en el monólogo, Ana Diosdado enfatiza las desigualdades de género en legislación al decir por boca de Nora que "las mismas leyes que consideraban a una mujer eternamente menor de edad, las mismas leyes que hacían depender para siempre de la tutela de alguien, que la convertían en algo que se maneja - en una muñeca, por ejemplo" la hubieran "condenado" (Diosdado 1977: 60). Más adelante, vuelve a incidir sobre la cuestión legislativa al traer a colación los resultados de una encuesta publicada en un periódico español (que no nombra) sobre "la capacidad jurídica de la mujer casada a examen" (1977: 61). Llegamos a este punto del monólogo, la autora parece perder el interés en mantener la farsa de que es Nora realmente la que está hablando y comienza a glosar con ironía los comentarios machistas que acompañaron a la publicación de dicha encuesta:

Voy a citar simplemente frases entresacadas (...) que me han llamado la atención por lo significativas. Por ejemplo: "Ciertas diferencias de trato - dice un caballero - no están basadas en una falta de consideración hacia ella (la mujer), sino en el propósito de dispensarle una particular tutela". Tutela. Otro de ellos opina: "Una presunción "juris tantum" debe establecerse en favor del marido por razón de su mayor capacitación y experiencia, por lo que debe ser él, naturalmente, quien dirija." No da explicaciones. Continúo: "La situación jurídica de la mujer debe cambiar por completo cuando esté casada - este es otro-. Hablar en este caso de igualdad de derechos entre marido y mujer es empeñarse en negar la esencia del matrimonio, que ha sido, es y será la misma a través de todos los tiempos. Es reincidir en aquella declaración pedante y modernista de la Constitución de 1931, cuando decía que el matrimonio se funda en la igualdad de derechos para ambos sexos. No nos dejemos llevar por un mal entendido sentimentalismo, pretendiendo subvertir la jerarquía dentro del matrimonio, establecida precisamente en beneficio de la mujer" tampoco lo explica este caballero. Otro más: "De un lado, hay que defender y proteger la personalidad de la mujer, más, de otro lado, todo se perdería si al reconocer a la mujer sus valores humanos y sus derechos naturales - este, como verán, ya da por sentado que no se le reconocen-, protegiendo su libertad y dignidad, pusiésemos en peligro su femineidad". Esta frase me hizo reflexionar mucho, me sumió en un verdadero mar de confusiones, y por más vueltas que le di no conseguí averiguar de qué modo podría poner en peligro mi femineidad, ni la de nadie, el hecho de que se me reconociesen mis valores humanos y mis derechos naturales (Diosdado 1877: 62). 
Como vemos, con su selección de fragmentos Ana Diosdado destaca aspectos de la legislación vigente que pese a ser abiertamente misóginos e incluso ilógicos, forman parte del status quo de la sociedad española del tardofranquismo. En ese sentido, las citas que ha escogido resultan muy útiles para hacerse una idea de los aspectos más controversiales de la legislación franquista en lo que a igualdad de género se refiere. Así, hace evidente hasta qué punto la mujer es considerada una menor que debe ser tratada de forma diferente, tutelada, dirigida, y jerárquicamente supeditada al hombre. No solo eso, sino que la defensa la igualdad de sexos no es sino un mero "sentimentalismo" ya que la mujer es más feliz si está supeditada al hombre, puesto que la jerarquía matrimonial la beneficia, una frase que recuerda al deseo de abnegación femenino al que había aludido Carmen Werner, como citamos al comienzo del artículo. Resulta de particular interés la discusión que hace del concepto de femineidad, o más bien del vacío semántico que ese concepto esconde, ya que nunca es claramente descrito por aquellos que cantan sus loores. Por ejemplo, con respecto al crítico que se lamenta de las mujeres que ponen "en peligro su feminidad", la autora señala que la frase la "sumió en un verdadero mar de confusiones" ya que no alcanzaba a comprender de qué modo su "feminidad ni la de nadie" podía ponerse en peligro por reconocerle los "valores humanos" y "derechos naturales" (1977:62). De este modo, Diosdado pone de manifiesto hasta qué punto la mística de la feminidad seguía presente en la España de la transición como elemento opresor de la libertad femenina.

Ana Diosdado cierra su monólogo con una reflexión final sobre la importancia del personaje de Nora para el teatro universal, recordando a las actrices importantes que encarnaron el papel. Hace énfasis en el hecho de que, aunque Ibsen haya sido frecuentemente acusado de "arremeter contra al matrimonio" lo que realmente hacía era criticar la hipocresía social y la falta de comunicación en el matrimonio (1977: 63). De esta forma, parece traer a cuestión la necesidad de llevar a cabo un debate serio sobre el divorcio, como demandaba la sociedad de hecho, la Ley del nulidad, separación y divorcio de 1981 fue una de las primeras leyes aprobadas en la Transición que corregían desigualdades jurídicas históricas entre hombres y mujeres. La cuestión del divorcio o de su imposibilidad sería un punto de conexión importante con la situación de las mujeres durante el franquismo, y como veremos, fue también enfatizado en la adaptación de 1983 y en la de 2015.

La segunda reescritura de Ana Diosdado es la versión de 1983 de Casa de muñecas. El texto presenta numerosas modificaciones, tanto estructurales (dos actos en vez de tres, además de "convertir en diálogos los monólogos, en escenas colectivas las clásicas sucesiones de escenas de dos en dos, en escenas colectivas las innumerables cartas") (Diosdado 1983: 7) como de contenido (añadidos, recortes y modificaciones que afectan también a la caracterización de los personajes). En este artículo señalaremos únicamente las diferencias más significativas, los cambios en la caracterización de Nora, Krogstad, y Helmer, y el polémico final.

Aunque no podemos detenernos a analizar pormenorizadamente el lenguaje, quisiera destacar los numerosos modismos y juegos lingüísticos que Ana Diosdado introduce en los diálogos para acercarlos al lenguaje coloquial: “ ¿Y si el día de Nochevieja me cae una teja y ahí me deja?" (1983: 11); "yo sé manejar muy bien a Torvald, tengo una mano izquierda..." (Diosdado 1983: 20); "me encerraba en el cuarto de planchar, y venga, y venga, hasta las tantas" (1983: 23); "vaya una idea más negra para unas Navidades" (1983: 41); "corramos un tupido velo" (1983: 50); "casi tenemos otra pelotera como esta" (1983: 55); "de tal palo tal astilla" (1983:88). En su momento los críticos destacaron la naturalidad lingüística que hacía el texto de Diosdado más "directo" y "flexible", que sonaba "bien", lo cual permitía "actualizar, 
sin traicionarlo, a Ibsen", fundiendo "fidelidad al autor y modernidad de expresión" (López Sancho 1983: 63).

Con respecto a Nora, los cambios se refieren exclusivamente a su caracterización física que parece indicar una fortaleza psicológica superior a la que el personaje demuestra en los primeros actos de la obra original. Amparo Baró (1937-2015), la actriz que encarnó a Nora tenía ya más de veinte años de carrera a sus espaldas y era conocida por su ademán enérgico, fuerte carácter, voz grave de fumadora y pelo corto. Fue criticada por no tener las condiciones físicas que según el crítico se asociaban al personaje: "el infantilismo, la dulzura inicial, la edad" (Haro Tecglen 1983). Este endurecimiento de Nora puede tener que ver con la tendencia a partir de los años 70 de destacar la fortaleza de la mujer frente a la debilidad del hombre en las representaciones de Casa de muñecas. El caso más conocido es la versión de 1975 de Liv Ullman en Broadway en la que el personaje de Helmer llevaba muletas; más reciente ha habido incluso versiones en las que los papeles masculinos estaban interpretados por enanos, como la versión de Lee Breuer estrenada en 2003. Por otra parte, el escoger a una actriz de fuerte carácter (y voz) como Baró para representar el papel infantilizado de la Nora de la primera parte de la obra, puede interpretarse como crítica implícita a las sujeciones franquistas que obligaban a las mujeres a ser "eternas menores".

Al mismo tiempo, la autora afirma en el prólogo que quiso "potenciar" en Krogstad "su indudable condición de víctima social" y hacerlo un personaje más simpático para el público (Diosdado 1983: 8). De hecho, una de las principales modificaciones que introduce Diosdado es que el recurso de la carta de Krogstad de la obra original donde dice que ya no va a denunciarlos, que es sustituido por una visita de Krogstad a la casa, de forma que los tres personajes confrontan directamente el asunto. Esa escena sirve para resaltar la mediocridad de Helmer frente a la mayor altura moral de los otros dos personajes. En la escena Krogstad busca la complicidad de Nora como puede verse en las siguientes acotaciones: "Krogstad cambia una mirada con Nora, una mirada de absoluto desprecio hacia el hombre que había" y "Krogstad mira a Nora con infinita compasión" (Diosdado 1983: 90). De esta forma, Krogstad se convierte en una piedra de toque moral sobre la hipocresía social de la época (que se refleja en la hipocresía social franquista): “¿Le asusten a usted las palabras, verdad? Los hechos no, pero sí las palabras. Es usted digna hija de nuestra sociedad y de su peculiar moral (Diosdado 1983: 36). En contraste, el personaje de Helmer se convierte en el principal villano, como vemos en el siguiente fragmento donde Krogstad se avergüenza de usar el chantaje con Nora y le echa la culpa a Helmer: "Si. Yo también me estoy dando asco a mí mismo. Los dos tenemos que agradecérselo a nuestro buen Torvald. No sé si usted podrá perdonarle algún día que me haya obligado a tratarla de esta forma. Yo, desde luego, no podré" (Diosdado 1983: 68). Con dicho envilecimiento las escenas finales de Torvald adquieren una nueva significación, particularmente en las que dice a Nora que deben seguir aparentando ser una familia feliz: "Has destrozado nuestra felicidad, pero de cara a los demás, esta familia va a seguir siendo una familia modelo" (Diosdado 1983: 89). Aunque en España la ley del Divorcio se había aprobado en 1981, la polémica seguía candente y era fácil relacionar este comentario con los argumentos que utilizaban los sectores más conservadores y asociados a la Iglesia para los que el divorcio era una vergüenza, y aunque el matrimonio sea infeliz, debe aparentar no serlo por mera apariencia. A lo largo de la obra se acentúa también la actitud machista, paternalista y posesiva de Helmer: "un hombre, con su amor propio, llevaría mal el deberle algo a su mujer" (Diosdado 1983: 23); "tu hazte cuenta de que naciste el día en que nos casamos" (1983: 45), "deberías bordar o pintar acuarelas. La actitud es mucho más estética" (Diosdado 1983: 80); "mi palomita 
es toda mía y yo la tomo cuando quiero" (1983: 81). Esto es particularmente evidente en la escena final, en la que Diosdado introduce un cambio importante:

NORA: Para que dejarlas de serlo [un extraño], sí que tendría que ocurrir un milagro, y yo, Torvald, ya no creo en milagros.

TORVALD: Pero yo quiero creer... ¿qué clase de milagro?

NORA: Que nos trasformáramos los dos... tanto tú como yo, hasta el punto de formar un verdadero matrimonio... ;Adiós, Torvald!

TORVALD: Nora... (Sale NORA, cerrando la puerta de la casa tras de sí. Casi a la vez, como una contrafigura suya, abre la puerta que lleva a la zona de los niños la pequeña EMMY). Nora... (Corre a refugiarse en brazos de su padre. Él la levanta, la abraza, la sienta en sus rodillas. Ante la niña, para quien aún sigue siendo "el hombre triunfador de las espaldas anchas", TORVALD se rehace, se afirma). ¿Se ha despertado mi niña?... ¿No ha tenido miedo mi ratoncito?... ¿Por qué? Papá está aquí, mi muñequita preciosa... Papá cuidará de ti, papá es muy fuerte, palomita... Mi niña no tiene por qué estar asustada, mi niña tiene quien la defienda, mi niña... Mi niña... Mi niña... (Y sobre su cantinela, meciendo la niña, las luces van desapareciendo: Todo seguirá igual) (Diosdado 1983: 99)

Así, en el final de Diosdado Torvald se queda sobre el escenario, abrazado a la niña, y parece querer reproducir en ella el trato que al comienzo de la obra había otorgado a Nora. Al parecer, en el estreno, el director de la obra decidió en el último momento cancelar algunas de las modificaciones textuales de Diosdado, entre ellas las líneas finales, ya que consideraba que con el nuevo final "no se reforzaba la imagen de la libertad de la mujer, que estaba en el texto original de Ibsen". El productor Manuel Mora añadió que el final de Diosdado era equívoco porque "Se puede interpretar que el padre es buenísimo y que queda abrazado a los hijos abandonados por la perversa madre o que, tal y como pretende Ana Diosdado, que Torvald anuncia en su hija la repetición de la historia con la madre" (El País, 29-2-1983).

La alteración del final indignó a Ana Diosdado que amenazó con hacer retirar la obra de cartelera, aunque finalmente los productores y la autora llegaron a un acuerdo y se volvió al final alterado de Diosdado. Estoy de acuerdo con los críticos en que este final es equívoco, ya que la clave de la crítica social que hace Diosdado se oculta en las acotaciones, especialmente la última ("Todo seguirá igual"). Es posible por tanto que una buena parte del público no entendiera la sutil crítica que hace al machismo arraigado de Torvald, y por extensión de la sociedad franquista. Desde luego, según algunos críticos ni el director ni la autora parecieron querer enfatizar "el aspecto feminista que muchos han querido ver en la obra no ha sido especialmente destacado" (García 1983; Haro Tecglen 1983). Opina lo contrario el crítico Carlos Gil Zamora, que llega a afirmar que la autora "ha pretendido ideologizar un conflicto que en Ibsen se trata de una forma más vital. Me refiero a la supuesta concienciación de la protagonista que aquí se nos hace ver como algo racional, algo que se va fraguando a lo largo del tiempo y que Ibsen lo planteaba de una forma más emocional" (Gil Zamora 1983). Por su parte, la escritora Carmen Laforet, conocida por haber dado voz a la subjetividad femenina que no encajaba en el ideal de domesticidad franquista con su novela Nada (1943), considera que la obra de Ibsen y la adaptación de Diosdado son "imprescindible[s]" en tanto que llaman la atención sobre las leyes patriarcales según las cuales "debe estar supeditada siempre al hombre", bajo "su tutela" apuntando así con cautela a la importancia de representar "ahora, hoy, en este momento" la obra (Laforet 1983), es decir, a la necesidad de hacer una denuncia social a la desigualdad de género a la que España había estado acostumbrada durante tantas décadas. 
Sin embargo, y como se puede leer en su "Antecrítica", Ana Diosdado afirmó que no había pretendido subrayar la vinculación feminista de la obra, para lo cual se escudó en las bien conocidas declaraciones del propio Ibsen sobre su voluntad de hablar de la "redención del género humano", y no solamente de "la emancipación de la mujer" (Diosdado 1983b: 62). Considero que esta declaración es incongruente a la luz de las referencias que se ocultan tras los textos de "Nora" y Casa de muñecas, que como hemos analizado hacen más evidentes las denuncias que había en el texto original, especialmente por buscar un paralelismo con la sociedad española, y de esta forma subrayar la actualidad del tema. Por otra parte, y de acuerdo con las teorías de la traductóloga feminista Luise von Flotow, en tanto que los traductores (adaptadora en este caso) eligen qué autor o qué libro diseminar, el mero hecho de seleccionarlo y presentarlo a un nuevo público, es una forma de activismo feminista (Flotow 2011:4). La vinculación de Casa de muñecas al feminismo ya existía antes de las intervenciones textuales de Diosdado, y dichas intervenciones, en mi opinión, únicamente acentúan el carácter reivindicativo de la obra. Como hemos visto en los ejemplos, Diosdado hace una crítica oblicua a la persistencia de la situación de desigualdad de las mujeres españolas en la transición, tras 40 años de dictadura franquista. En ese marco interpretativo es clave el testimonio de la autora Carmen Laforet, como perspicaz intérprete de la cultura en la que ha vivido toda su vida.

\section{Reescritura de Lucía Miranda}

A principios de 2015, Lucía Miranda comienza a trabajar en un proyecto de laboratorio de teatro documental bajo encargo del Teatro Nacional en el que se pretende explorar las conexiones de la obra de Ibsen con la historia de las mujeres, y más en concreto con la memoria colectiva de las mujeres españolas del franquismo. Su objetivo de reescribir críticamente la memoria colectiva femenina del franquismo se hace explícito desde los inicios del proyecto. El teatro documento o documental trabaja con testimonios, entendidos como historias personales para construir obras teatrales con elementos de collage que tengan relevancia histórica y/o social, jugando así con los límites entre la realidad y la ficción (Rodríguez 1995:117). Este tipo de teatro es muy habitual en los escenarios españoles de las últimas décadas (López Mozo 2017). El proyecto de Nora, 1959 incluyó también diversos talleres, exposiciones y mesas de trabajo abiertas al público general para familiarizarse con la obra original y con el contexto histórico y cultural español.

Las modificaciones textuales de Nora 1959 son más evidentes que las que realiza Ana Diosdado en su sutilmente retocada Casa de muñecas porque afectan profundamente a la estructura de la obra, recortándola considerablemente y añadiendo materiales adicionales que no pertenecen al original, que son intercalados con las principales escenas de la obra Ibsen. Nora, 1959 no está dividida en tres actos sino que hay una sucesión de veinte escenas y un epílogo (el documental sonoro de las mujeres) sin descanso en medio, con lo que toda la obra dura unos 90 minutos. Si bien el texto es significativamente más corto que el original la autora ha respetado los momentos más importantes de la trama, es decir, no introduce modificaciones de las escenas originales, o de la caracterización de personajes como había hecho Diosdado, sino que recorta algunas de ellas para introducir material nuevo que funciona como historia dentro de la historia. Este material nuevo gira fundamentalmente en torno al mundo de la radio, que se utiliza para representar la principal forma de evasión de las mujeres de los años 50 y funciona como una herramienta de ambientación teatral muy sugestiva (Ruiz Gómez 2017). Originalmente la autora había pensado usar el cine en blanco y negro con la misma función y hacer así "teatro en blanco y negro" pero lo descartaron por cuestiones de presupuesto (De la 
Sierra 2015). Durante la función se intercalan las escenas de Ibsen con locuciones de diversas escenas de distintos programas de radio, como un consultorio o una radionovela policiaca, además de la publicidad, recreadas por los mismos cinco actores que interpretan los personajes principales. Como ha explicado la propia Miranda, la radio pretende simbolizar la domesticidad forzada de las mujeres en tanto que "era la [única] forma en que las mujeres de aquellas décadas 40, 50 y 60 se relacionaban con el exterior". Además "de la misma manera que la Nora de Ibsen tiene prohibido comer peladillas porque a su marido no le gusta", la Nora de Miranda "tiene prohibido escuchar un serial de radio muy famoso en la época que se llamaba En busca del culpable" ya que su marido considera que es un contenido inadecuado para una mujer (Miranda en CDN 2015: 9-10). Además, la obra busca la complicidad y participación del público, de forma que durante de la obra hay interacción directa de uno de los actores (que tiene un doble papel de músico y portero) con el público, a modo de "role-play" (Navarro 2015).

Una de las innovaciones más interesante desde el punto de vista de la crítica feminista es la introducción de escenas de música y baile para reforzar momentos clave de la obra, en opinión de la autora, y que sirven para explorar la subjetividad emocional del personaje de Nora. En el caso de la primera escena, en la que los personajes de Nora y Cristina reproducen escenas de su infancia mientras son movidas por los personajes masculinos de la obra como si fueran muñecas, la escritora ha afirmado, en entrevista privada (2016), que diseñó este flashback porque quería explorar la amistad de las dos protagonistas femeninas, que veía insuficientemente reflejada en el original de Ibsen. En ese flashback hay referencia explícita a los ejercicios grupales de calistenia que promovía la Sección Femenina como una forma adecuada y femenina de ejercitar el cuerpo e introducir el adoctrinamiento ideológico desde edades tempranas (Domingo 2007: 37-48). La Sección Femenina tenía un papel muy importante en la educación de las niñas españolas, y dentro de su programa se pretendía inculcarles "la vocación al servicio del marido y a los hijos, y de desempeño fiel de las labores domésticas" (2007: 37). En la segunda escena, de más de cinco minutos, se mezclan el ensayo del famoso ensayo de la tarantela (que se convierte en un sensual mambo que era un tipo de canción muy popular en los años 50) con el baile de Navidad que en el original no se representaba sobre las tablas. De esta forma, hay una transición entre los primeros compases del baile, en que Nora baila sola e insegura, y luego con más seguridad tras ser rodeada y escrutada por sus compañeros, que se acaban uniendo al baile, cantando a gritos e invitando al público a participar. Así, el baile funciona como un elemento de refuerzo de la autoestima del personaje, que ayuda para comprender la transición emocional entre la Nora del comienzo y del final de la obra. Sobre esta escena es importante recalcar que Nora va vestida con pantalones y una camisa con generoso escote que muestra su ombligo (imitando cómo iba vestida una cantante de la época), un tipo de indumentaria que rompe con el estricto decoro que se esperaba de las mujeres de los años 50 (este aspecto es destacado, por ejemplo, por una de las entrevistadas del documental sonoro). Otra alteración significativa es que el actor que interpreta a Torvald también interpreta a su hijo (único, en esta obra), de forma que la infantilización a la que somete Torvald a Nora con sus comentarios paternalistas se ve reflejada en sus propios actos infantiles cuando interpreta al personaje del niño, corriendo y chillando sin pantalones por el escenario.

Casi cuarenta años después del fin del franquismo, la autora Lucía Miranda no tiene problema alguno en abrazar una interpretación feminista de la obra, y su intención de utilizarla con fines pedagógicos para visibilizar un aspecto importante de la historia reciente de España: la situación de desigualdad de las mujeres durante el Franquismo. Ese elemento feminista es enfatizado en todas las entrevistas que concede, y en todas las reseñas de la obra (Navarro 2015, 
de las Heras 2015, de la Sierra 2015, Corroto 2015, Vallejo 2015, Vila, 2015, Santos 2015, Otheguy Rivera 2015). Por tanto, el proyecto se construye desde el principio desde la denuncia feminista y con una perspectiva histórica clara, a la que habría que añadir un matiz de historia familiar:

Hace tiempo que al pensar en Nora, la protagonista de Casa de Muñecas de Ibsen pienso en mi abuela. ¿Y si mi abuela fuera Nora? ¿Y si a través de Nora contáramos las historias de nuestras abuelas? Las vidas que Nora pudo vivir después de abandonar a su familia; quién era antes de conocer a su marido; quiénes fueron sus hijos cuando ella se fue; como hay una vida que no vives, porque elegiste otra (Miranda 2015: contraportada)

De esta forma, Lucía Miranda explica que para su adaptación se inspiró en la vida de su abuela, que abandona a su marido a finales de los 50 para comenzar una nueva vida por su cuenta (llevándose a sus hijos) y que crea el "espectáculo para entenderla, o quizá para salvar una deuda con ella" (Miranda en CDN 2015: 10). La escritora afirma que pretende hacer un homenaje, no solo a su abuela, sino también a todas las mujeres de su generación. Este aspecto es subrayado por la inclusión de un emotivo documental sonoro que se emite al final de la función, que incluye fragmentos de diversas entrevistas a mujeres que vivieron en la España de los cincuenta, preguntándoles por "cómo era ser mujer en aquella época, si se sentían libres, qué hubieran hecho en su vida de haber podido..." (Santos 2015). Por tanto, la obra tiene pretensiones de documentar la historia oral reciente, y ponerla a disposición del público para su revisión crítica y hacer evidentes los paralelismos entre la "España nacional-católica de 1959" (Otheguy Riveira 2015) y la Noruega de finales del siglo XIX. Como exclama uno de los críticos de la obra:

¡Con qué facilidad encaja el argumento de Casa de muñecas en la España de finales de los 50 ! Lucía Miranda hace viajar a los protagonistas de la obra de Ibsen en el tiempo y el espacio sin modificar apenas el original: la ciudadana de a pie de la Noruega anterior a la victoria de las sufragistas y la ama de casa prototipo del franquismo respiraban idéntico aire viciado (Vallejo 2015).

El significado político de la obra se hace evidente para los espectadores a la luz de dos de las principales reivindicaciones que han agitado la opinión pública de la España reciente: la memoria histórica (referida a la Ley 52/2007, de 26 de diciembre "por la que se reconocen y amplían derechos y se establecen medidas en favor de quienes padecieron persecución o violencia durante la guerra civil y la dictadura") y las distintas formas de violencia machista, entre las que se incluye la discriminación. Relativo a este último aspecto, enfatizan los críticos que la obra pretende denunciar la doble discriminación a la que las mujeres españolas han sido sometidas: los dos "yugos" del "franquismo" y el "machismo" (Corroto 2015). Aunque las referencias sean fundamentalmente históricas, la obra tampoco ha perdido relevancia en tanto que mientras el machismo siga vigente en la sociedad todas las mujeres "hoy y siempre" son Nora, aunque la Nora de hoy en día "no está atada a la pata de la mesa", sino que "sus maridos, sus novios, sus parejas, sus amantes la controlan a través de las redes, espiando sus comunicaciones por móvil o quitándoselos a la fuerza y viendo sus mensajes y, desgraciadamente, con mayor frecuencia de la que todos quisiéramos, hay demasiadas Noras a quienes no les da tiempo a salir de casa y llegan a perder la vida a manos de sus controladores (Vila 2015).

En lo relativo a la memoria histórica, los críticos apuntan a la domesticidad forzada que imperaba en el franquismo ("esa inconsciente cárcel que era su hogar”) (De las Heras 2015). 
Esta reclusión se hace manifiesta en la sobria puesta en escena de Lucía Miranda, un oscuro interior con escasos muebles salvo una radio, un piano, un sillón, una lámpara, un costurero, y unas letras sobredimensionadas que rezan "ON AIR" que tienen una doble función, resaltar la conexión con la radio, que ahora explicaremos, y ser ventanas simbólicas desde donde Nora contempla el exterior, el espacio público al que no le está permitido acceder. Como ha apuntado Lucía Miranda, la ventana tenía una significación especial en la vida de las mujeres durante el franquismo, relacionándolo con las teorías feministas sobre la "mujer ventanera" que escapa de la domesticidad recogidas en el libro Desde la Ventana (1987) de Carmen Martín Gaite (Miranda en Santos 2015). Al final de la obra, la Nora de Miranda sale por la ventana, lo que para la autora y los críticos debe interpretarse como un gesto de esperanza (Miranda 2015; Corroto 2015; Santos 2015; De las Heras 2015). Inicialmente Miranda había incluido un final en el que contaba lo que le pasaba a Nora después, pero en la sesión de ensayo con público este final fue criticado ya que los espectadores "abogaron por su libertad para imaginarse el final de la historia, darle un desenlace positivo, negativo, o dejarlo abierto" (Santos 2015). De esta forma, la obra se cierra con un final empoderado para la mujer, que se refuerza con el emotivo documental sonoro, que despertó risas, lágrimas y aplausos en el público (Miranda, entrevista privada 2016). De esta forma, Miranda lleva a cabo su proyecto de animar a los españoles y españolas de hoy día, de varias generaciones, a reexaminar críticamente la historia reciente, y poner en valor los numerosos avances que ha sufrido la sociedad española en materia de género desde los años cincuenta hasta ahora.

\section{Conclusiones}

En las primeras páginas de este artículo hemos ofrecido una historia sintética de las reescrituras españolas de Casa de muñecas, haciendo manifiesta así la gran variedad de adaptaciones libres para el cine, la televisión y el teatro que existen en la cultura hispanohablante, aunque muchas de ellas no hayan sido estudiadas, ni tan siquiera inventariadas todavía. Hemos señalado así un importante vacío de conocimiento del que este artículo solamente pretende cubrir una pequeña parte. Este repaso histórico demuestra que la supuesta ausencia de interés del público hispánico en la obra no es tal, sino que esta cifra limitada se debe a una falta de registro sistemático de las puestas en escena en español, que contraste con la cobertura mucho más eficaz de otras áreas lingüísticas como la inglesa, francesa, alemana o escandinava.

Esta historia sintética sirve como contexto para explicar las tres reescrituras críticas con el franquismo, explícita o implícitamente, que hemos estudiado en este artículo. Estos tres textos buscan conectar, revisar y reescribir una obra de teatro clásico, aclamada universalmente, a la luz de un momento concreto de la historia reciente de España. Como sugerimos en las primeras páginas, es probable que la rica variedad de reescrituras hispanohablantes tenga una conexión directa con el hecho de que España (y otros países hispanohablantes) estuvo atrapada en una dictadura profundamente restrictiva con los derechos humanos, y particularmente los de las mujeres, cuya libertad de movimiento y agencia estaba significativamente reducida. En paralelo, la ideología dominante abogaba por un enaltecimiento de la mística de la feminidad, que condenaba a las mujeres a la sumisión a los roles de madre y esposa. Se ha señalado con frecuencia que el retorno a la domesticidad asfixiante que propugnaban las autoridades morales franquistas supuso un "doble retraso" para el feminismo español en tanto que las mujeres españolas debieron luchar en los años 70 y 80 por conseguir las mismas libertades que habían conseguido en los años 30 (Núñez Puente 2004: 10). Algo similar ocurre en otros países 
hispanohablantes donde triunfaron distintas dictaduras a lo largo del siglo XX, de forma que las mujeres hubieran de recorrer dos veces, en dos momentos históricos distintos, el mismo camino en la lucha hacia la igualdad de género. En mi investigación defiendo que es este hecho justamente el que está detrás no ya de la escasez, sino, al contrario, de una muy poco estudiada abundancia de adaptaciones de Casa de muñecas en el ámbito hispánico (para las adaptaciones chilenas ver Helland 2015: 47-78), y particularmente en España.

Como hemos señalado, las reescrituras de Ana Diosdado incluyen numerosas denuncias con respecto a la desigualdad de género de la época franquista, fundamentalmente en torno a los derechos legales, el machismo de la sociedad, la domesticidad asfixiante, y la hipocresía social. Si bien el tono reivindicativo de "Nora" es evidente, en el caso de su adaptación Casa de muñecas, la crítica feminista al contexto post/franquista aparece camuflado en la habitual afirmación de que como dijo Ibsen, se trata de una obra que reivindica los derechos de toda la humanidad, y no solo de las mujeres. Considero que la voluntad de no declararse abiertamente feminista de la autora tiene que ver más con una estrategia comercial que debe entenderse en el contexto histórico, ya que las modificaciones textuales son demasiado numerosas y tiene una clara conexión feminista que hemos señalado, y que Carmen Laforet explicitó en su aguda crítica.

En contraste, la reescritura de Lucía Miranda proclama abiertamente su intención feminista, y fue recibida como tal por la crítica y el público, que apreció especialmente la conexión con la historia española. Esto tiene mucho que ver con el cambio de mentalidad de la sociedad española con respecto al feminismo, y también al rescate de la memoria histórica. No obstante, quisiera hacer hincapié en la frecuente mención de los críticos en la pertinencia del tema de la igualdad entre hombres y mujeres, pues aunque en España ha habido muchas mejoras para las mujeres durante el tardofranquismo, la transición, y sobre todo en el nuevo milenio, todavía queda camino por recorrer hasta alcanzar la igualdad real. El que la obra de Ibsen siga siendo representada y despierte comentarios semejantes, una y otra vez, en casi cualquier puesta en escena de la obra, no ya solo en España, sino en cualquier país del mundo, no es sino prueba de que las personas cada vez somos conscientes de que la reivindicación de Nora, la lucha por la igualdad efectiva entre mujeres y hombres, es una de las principales preocupaciones de nuestro siglo.

Pese a que las tres obras pueden ser consideradas reescrituras feministas que pretenden denunciar la situación de desigualdad de género en la que vivían las mujeres franquistas, existe una diferencia fundamental entre la actitud de ambas autoras. La obra de Miranda, pese a su denuncia, se escribe desde el optimismo, buscando que el público sepa más sobre su pasado, y también que se reconcilie con este, y que le sirva para analizar mejor el presente. Esto es especialmente evidente en la voluntad explícita de la autora de que el público estuviera formado por hombres y mujeres de diferentes edades, y que se estableciera un diálogo intergeneracional a la salida del teatro. En contraste, el carácter de las obras de Diosdado es circunspecto, áspero en ocasiones, especialmente en el caso de "Nora", que interpela directamente al público para que reflexione sobre la situación de las mujeres en España, y la postura antifeminista o directamente misógina del sistema, ejemplificado con las citas de expertos en materia jurídica. Esto tiene mucho que ver con la distancia histórica con respecto al momento traumático de la dictadura. En su primera reescritura Diosdado está denunciado una situación todavía presente, que desea cambiar, y en la segunda, aunque ha habido cambios significativos durante la transición, está haciendo evidente que todavía quedaba mucho camino hacia la igualdad efectiva de los hombres y las mujeres en España. En cambio, Miranda, desde los grandes 
avances en materia de género que ha habido en España en las últimas décadas prefiere buscar la risa más que el llanto o el enfado en el público; recordar, conmemorar, reivindicar, pero desde la perspectiva de quien sabe que la sociedad española ha superado buena parte de lo que denuncia.

\section{Bibliografía}

Aaltonen, Sirkku. 2000. Time-Sharing on Stage: Drama Translation in Theater and Society. Clevedon, Multilingual Matters.

Anon. 1983. "Ana Diosdado consigue que se respete su versión íntegra de "Casa de muñecas". El País, 29 de febrero, 1983.

http://www.march.es/Recursos_Web/Culturales/teatro/Prensa/PA292.pdf

Centro Dramático Nacional (CDN). 2015. "Nora, 1959”. Cuadernos pedagógicos 83, 8-11.

Corroto, Paula. 2015. “Nora, 1959: El machismo que mató a nuestras abuelas". El diario, 12 de noviembre, 2015. http://www.eldiario.es/cultura/teatro/machismo-matoabuelas_0_451455681.html

De la Sierra, Reyes M. 2015. "Entrevista: Lucía Miranda presenta Nora, 1959”. Experpento, 15 de noviembre, 2015. http://experpento.com/lucia-miranda-presenta-nora-1959/

De las Heras Martín, Rut. 2015. “Una Casa de muñecas durante el franquismo”. El País, 16 de noviembre,

2015.

https://elpais.com/ccaa/2015/11/12/madrid/1447353656_663988.html

Diosdado, Ana. 1977. "Nora". En Seis Conferencias en torno al Día Mundial del Teatro, Madrid 1975. Madrid, Ministerio de Información y Turismo, 56-63.

Diosdado, Ana. 1983. “Antecrítica”. ABC, 2 de febrero, 1983, 62.

Domingo, Carmen. 2007. Coser y cantar. Las mujeres bajo la dictadura franquista. Barcelona, Lumen.

Dubatti, Jorge 2006. "Estudio preliminar". En Ibsen, Henrik: Una Casa de muñecas. Un enemigo del pueblo. Trad. Celia Chamatropoulos. Buenos Aires: Colihue.

Estatutos de la Sección Femenina. 1939. Salamanca, Imprenta Cervantes.

Flotow, Luise von. 2011. Translating Women. Ottawa, University of Ottawa Press.

Gil Zamora, Carlos. 1983. "Tragedia pero menos". Egin 20 de agosto, 1983. http://www.march.es/Recursos_Web/Culturales/teatro/Prensa/EG3.pdf

Grovas Hajj, Víctor 2008. Ibsen a la mexicana. Mexico: Fontanamara.

Guerrero, Isabel, y Alba Saura Clares. 2016. "Ibsen pop: Nuevo realismo, mezcolanza estética y cultura pop en la representación contemporánea de Ibsen”. Anagnórisis: revista de investigación teatral 13: 6-31.

Hale, Terry and Carole-Anne Upton. 2000. Moving Target: Theatre Translation and Cultural Relocation. Manchester, St Jerome.

Haro Tecglen, Eduardo. 1983. "En busca de Ibsen". El País, 4 de febrero, 1983. http://www.march.es/Recursos_Web/Culturales/teatro/Prensa/PA288.pdf 
Helland, Frode. 2015. Ibsen in Practice: relational readings of performance, cultural encounters and power. London, Methuen.

Holledge, Julie, Frode Helland, Joanne Tompkins, \& Jonathan Bollen. 2016. A Global Doll's House. Ibsen and Distant Visions. New York, Palgrave Macmillan.

Holledge, Julie. 2011. "Sharing A Doll's House with Islamic Neighbours". Canadian Review of Comparative Literature 38 (2): 154-171.

Ibsen, Henrik. 1983. Casa de muñecas. Revisión Ana Diosdado. Madrid, MK. [Ibsen \& Diosdado]

Ibsen, Henrik. 2005-2010. Henrik Ibsen Skrifter [HIS]. Edición online. www.ibsen.uio.no/forside.xhtml

IbsenStage. 2015. https://ibsenstage.hf.uio.no/

Isern y Galcerán, Carmen. 1948. La mujer en la vida del trabajo. Madrid, Gobernación.

Laforet, Carmen. 1983. "Casa de Muñecas, realismo y feminismo”. El País 29 de enero, 1983. http://www.march.es/Recursos_Web/Culturales/teatro/Prensa/PA324-A.pdf

La Zona Kubik. 2015. “Nora, 1959”. http://lazonakubik.com/nora-1959/

Lefevere, André. 1992. Translation, rewriting and the manipulation of literary fame. London, Routledge.

López Mozo, Jerónimo. 2017. "Mapa del teatro documental en los albores del siglo XXI en España”. En El teatro como documento artístico, histórico y cultural en los inicios del siglo XXI. Ed. José Romera Castillo. Madrid, Verbum. 23-41

López Sancho, Lorenzo. 1983. "Casa de muñecas tratada como un Ibsen clásico de plena actualidad". $A B C, 4$ de febrero, 1983, 63.

http://www.march.es/Recursos_Web/Culturales/teatro/Prensa/ABC16420.pdf

Muñiz, Iris F. 2016. "La España Moderna y la recepción temprana de Ibsen en España: en busca de la identidad del desconocido primer traductor español". Cartas Hispánicas 006: 127.

Muñiz, Iris. 2018. A Doll's House of their own. Gregorio and María Martínez Sierra's feminist rewritings of Ibsen in Silver Age Spain. Tesis doctoral. Oslo: University of Oslo.

Minier, Marta. 2014. "Definitions, Dyads, Tryads and Other Points of Connection in Translation and Adaptation Discourse". Translation and Adaptation in Theatre and Film. Ed. Katja Krebs. London, Routledge. 13-35.

Miranda, Lucía. 2015. Nora, 1959. Madrid, Centro Dramático Nacional. Libro y grabación.

Molinero, Carme. 1998. "Mujer, franquismo y fascismo: la clausura forzada en un mundo pequeño". Historia social 30, 97-117.

Moraga García, María de los Ángeles. 2008. "Notas sobre la situación jurídica de la mujer en el Franquismo". Feminismo/s 12, 229-252

Morcillo, Aurora G. 2013. "El género en lo imaginario. El ideal católico femenino y estereotipos sexuados bajo el franquismo". En Represión. Resistencia. Memoria. Las mujeres bajo la dictadura franquista. Ed. Mary Nash. Granada, Comares. 71-93.

Moreno, Mónica. 2013. "La dictadura franquista y la represión de las mujeres". En Represión. Resistencia. Memoria. Las mujeres bajo la dictadura franquista. Ed. Mary Nash. Granada, Comares. 1-21. 
Navarro, Regina. 2015. "Redescubriendo a Nora". Ritmos 21, 19 de noviembre, 2015. https://www.ritmos21.com/14166/redescubriendo-a-nora.html

Núñez Puente, Sonia. 2004. Una historia propia. Historia de las mujeres en la España del siglo $X X$. Madrid, Pliegos.

Otheguy Riveira, Horacio. 2015. "Nora 1959, un brillante ejercicio en torno a Casa de muñecas”. Culturamás, 19 de noviembre, 2015.

http://www.culturamas.es/blog/2015/11/19/nora-1959-un-brillante-ejercicio-en-tornoa-casa-de-munecas/

Pérez-Resilla, Eduardo. 2009. "La mujer y las relaciones de pareja en el teatro de Ibsen". En Las hermanas de Nora: Casa de muñecas en clave feminista, ed. Rosario Ruiz Franco. Madrid, Embajada de Noruega.

Rodríguez, Rafael. 1995. "Fundamento y memoria del teatro documento". ADE: Revista de directores de escena de España, 41-42, 117-119

Ruiz Franco, Rosario. 2007. ¿Eterna menores? Las mujeres en el franquismo. Madrid, Biblioteca Nueva.

Ruiz Gómez, Sara. 2017. "La radio como herramienta de ambientación teatral: el caso de Nora, 1959”. En Libro de Actas del V Congresso Internacional Cidades Criativas, coord. por Luís Alberto Alves, Francisco García García, y Pedro Alves, págs. 416-429.

Sánchez López, Rosario. 2007. Entre la importancia y la irrelevancia: Sección Femenina de la República a la Transición. Murcia, Editorial Regional de Murcia.

Santos, Carmen. 2015. "Nora 1959: Ibsen en la posguerra española". ABC, 20 de noviembre, 2015 http://www.abc.es/cultura/cultural/abci-nora1959-ibsen-postguerra-espanola201511202013 noticia.html

Siguán, Marisa. 2003. "Ibsen en España”. Historia del teatro español. Volumen 2: Del Siglo XVIII a la época actual. Coord. Javier Huerta Calvo. Madrid, Gredos. 2155-2179.

Tessada Sepúlveda, Teresa. 2012. "Modelando el bello sexo: El modelo femenino en las dictaduras de Franco y Pinochet a través de las revistas femeninas". Investigaciones históricas 32, 263-282.

The Cross Border Project. 2015. "Proyecto Nora, 1959". http://www.thecrossborderproject.com/nora1959/

Vallejo, Javier. 2015. “A Nora le sobra el caudillo". El País, 9 de noviembre, 2015. https://elpais.com/cultura/2015/11/18/actualidad/1447873461_348756.html

Vila, José Miguel. 2015. "Nora 1959 de Lucía Miranda, un espectáculo redondo, partiendo de 'Casa de muñecas' de Ibsen”. Diario crítico, 23 de noviembre, 2015. https://www.diariocritico.com/noticia/490099/teatro/nora-1959-de-lucia-miranda-unespectaculo-redondo-partiendo-de-casa-de-munecas-de-ibsen.html

Werner, Carmen. 1954. Convivencia social. Madrid, Delegación Femenina de la F.E.T. y de las J.O.N.S. 